\title{
Bimaterial Composites via Colloidal Rolling Techniques: I, Microstructure Evolution during Rolling
}

\author{
Mohan Menon*,t \\ Department of Materials Science and Engineering, University of Michigan, Ann Arbor, Michigan 48109-2136
}

I-Wei Chen ${ }^{*}$

Department of Materials Science and Engineering, University of Pennsylvania, Philadelphia, Pennsylvania 19104-6272

\begin{abstract}
Laminate composites of $\mathrm{Al}_{2} \mathrm{O}_{3}$ and $\mathrm{ZrO}_{2}$ fabricated by repeated rolling and folding are demonstrated using aqueous slurries of ceramic powders without any plasticizers or binders. Crack-free composites with a layer thickness of 4-60 $\mu \mathrm{m}$ have been obtained. A novel interface instability during the rolling of bimaterial slurries, which leads to the entrapment of the rheologically harder phase in the softer phase, also has been discovered. This discovery has been exploited to obtain layered materials, by matching the yield stress of the slurries, or cellular materials with the desired included phase, by mismatching the yield stress of the slurries. Adjustment of the yield stress can be realized by varying only the $\mathrm{NH}_{4} \mathrm{NO}_{3}$ salt concentration while keeping the pH and the solids loading (64 vol\%) constant.
\end{abstract}

\section{Introduction}

$\mathrm{C}$ ONTEMPORARY techniques ${ }^{1-12}$ for laminate fabrication involve building the laminate layer by layer. The starting layer can be fabricated using tape casting or rolling. For example, Clegg and co-workers ${ }^{1,2}$ fabricated $\mathrm{SiC}$ and graphite starting layers as well as laminates by rolling their ceramic suspensions in a polymer binder. In other techniques, each layer is sequentially cast ${ }^{3-11}$ or deposited ${ }^{12}$ to form the laminate geometry. These procedures are time consuming. In addition, composites of very fine layers are difficult to obtain, because it is relatively difficult to fabricate and handle starting layers that have a small thickness.

One ancient practice of making composites involves repeated forging and folding of the workpiece. This method, for example, was practiced by blacksmiths in various cultures to make high-quality swords using iron that contains a large amount of inclusions. ${ }^{13}$ The large deformation that is rendered by repeated forging and folding breaks the inclusions down into very fine stringers that strengthen, rather than weaken, the "composite." This concept of microstructure refinement can be extended to laminate fabrication by combining the rolling and folding operations repeatedly. It is a process that is used by bakers to make pastries and also can be used to expedite laminate fabrication.

In this study, repeated rolling and folding of coagulated

D. S. Wilkinson—contributing editor

\footnotetext{
Manuscript No. 190322. Received March 16, 1998; approved June 21, 1999

This research was supported by the U.S. Dept. of Energy (Basic Energy Sciences, BES), under Grant No. DE-FG02-97ER45637-A000.

${ }^{*}$ Member, American Ceramic Society.

${ }^{\dagger}$ Ph.D. candidate at The University of Michigan. Now at Dept. of Materials Science and Engineering, University of Illinois, Urbana, IL 61801.
}

aqueous slurries of $\mathrm{Al}_{2} \mathrm{O}_{3}$ and ceria-doped tetragonal zirconia polycrystals (Ce-TZP) for laminate fabrication without any plasticizer or binder will be explored. The colloidal behavior of the constituent powders ${ }^{13-16}$ and the mechanical properties ${ }^{3-7}$ of this composite system have been studied extensively. Various forming techniques ${ }^{3-12}$ have been used to fabricate this composite, some of which report very good mechanical properties such as high toughness. In our study, we determined that the rolling of a bimaterial strip with constituent layers that have different flow stresses could lead to interfacial instability. This phenomenon resulted in waviness of the interface between the layers. In extreme cases, this method led to further breakup of the laminate geometry into a cellular geometry. We have exploited this novel phenomenon to control the microstructure of the composite just by controlling the rheology of the constituent slurries.

In this paper, the processing procedure before firing and the microstructure that is observed after firing are described, to emphasize the aspect of composite fabrication and the laminate/cellular transition. In two subsequent papers, we will further report the sintering characteristics ${ }^{17}$ and mechanical properties $^{18}$ of these composites.

\section{Experimental Procedure}

\section{(1) Suspension Preparation}

Aqueous suspensions of $\mathrm{Al}_{2} \mathrm{O}_{3}$ and $\mathrm{Ce}-\mathrm{TZP}$ were prepared using the following method. The starting $\mathrm{Al}_{2} \mathrm{O}_{3}$ powders (Tamei TM-D, Biesterfeld U.S., New York) had an average particle diameter of $0.1 \mu \mathrm{m}$ and a specific surface area of 14 $\mathrm{m}^{2} / \mathrm{g}$, and the Ce-TZP powder (TZ-12CE, Tosoh, Tokyo, Japan) had an average particle size of $0.2 \mu \mathrm{m}$ and a specific surface area of $9.4 \mathrm{~m}^{2} / \mathrm{g}$. $\mathrm{Al}_{2} \mathrm{O}_{3}$ was doped with $0.1 \mathrm{wt} \%$ of $\mathrm{MgO}$ by adding $\left(\mathrm{Mg}\left(\mathrm{NO}_{3}\right)_{2}\right.$ to a dispersed $\mathrm{Al}_{2} \mathrm{O}_{3}$ suspension. Then, this mixture was dried at $85^{\circ} \mathrm{C}$ and calcined at $400^{\circ} \mathrm{C}$ for $2 \mathrm{~h}$. The powders of both doped $\mathrm{Al}_{2} \mathrm{O}_{3}$ and Ce-TZP were dispersed in deionized water at $\mathrm{pH} 2.0$ and attrition milled, using $\mathrm{Al}_{2} \mathrm{O}_{3}$ media. Readjustments of the $\mathrm{pH}$ were made by adding $\mathrm{HNO}_{3}$ or $\mathrm{NH}_{4} \mathrm{OH}$. The milled suspensions were stirred for $24 \mathrm{~h}$ and then $\mathrm{NH}_{4} \mathrm{NO}_{3}$ salt was added. Adjustments of the $\mathrm{pH}$ after the salt addition were made whenever necessary. Salt concentrations in all the $\mathrm{Al}_{2} \mathrm{O}_{3}$ suspensions were $2.2 \mathrm{M}$, and the salt concentrations were $2.2 \mathrm{M}, 3.3 \mathrm{M}$, and $3.8 M$ in the Ce-TZP suspensions.

\section{(2) Pressure Casting}

Pressure filtration at $0.42 \mathrm{MPa}$ was used to prepare highdensity suspensions. The solids loading of the consolidated body was calculated using the volume of initial suspension and the volume of water that was removed during filtration. These high-density suspensions will be referenced as "doughs" in the rest of the paper. Although additional processing of these 
doughs usually was performed within hours of preparation, the bodies retained the moisture for a few weeks if they were stored in an environment of saturated humidity.

\section{(3) Rheological Measurements}

Measurements of the steady-state viscosity at various shear rates were made in a computer-controlled constant-stress rheometer (Bohlin, Cranbury, NJ), using a cup-and-bob geometry. The dough was loaded into the rheometer and left undisturbed for $500 \mathrm{~s}$ to attain equilibrium. Then, a stress was applied and the resultant steady-state viscosity and shear rate were measured after $240 \mathrm{~s}$, before the applied stress was incrementally increased, and the procedure was repeated. To determine the yield stress, a stress was applied and the resultant plastic strain was measured. Then, this procedure was repeated for increasing stress at a rate of $6.67 \mathrm{~Pa} / \mathrm{s}$. In a typical test, thirty such stress increments were made per minute. If no plastic strain was detected at any stress increment in that minute, the applied stress interval was increased and the above-described measurements were repeated until a plastic strain was measured. Then, a strain rate was estimated from the ratio of the strain increment to the time interval. Fitting the shear-stress $(\tau)$ /shear-rate $(\dot{\gamma})$ data using Casson's model, ${ }^{19}$

$$
\tau^{1 / 2}=m \dot{\gamma}^{1 / 2}+\tau_{\mathrm{y}}^{1 / 2}
$$

the yield stress, $\tau_{\mathrm{y}}$, was determined by extrapolating the data to $\dot{\gamma}=0$ using a straight line.

\section{(4) Rolling Mechanics}

Rolling was performed in a twin-roller mill, using a modified commercial noodle machine (Model 150, Atlas, Italy), following the procedure below (see Fig. 1 for a schematic):

(1) Doughs of $\mathrm{Al}_{2} \mathrm{O}_{3}$ and $\mathrm{Ce}-\mathrm{TZP}$ were separately rolled into tapes of uniform thickness (1-2.5 mm).

(2) The $\mathrm{Al}_{2} \mathrm{O}_{3}$ and $\mathrm{Ce}$-TZP tapes were placed on top of each other and rolled to achieve a thickness reduction of $50 \%$.

(3) This composite then was folded and rolled to achieve a thickness reduction of $50 \%$.

(4) Step (3) was repeated $N$ times.

In the above description, the $50 \%$ reduction per pass was obtained by keeping the gap between the rollers the same as that in the original tape thickness. This reduction corresponds to a true strain of $\ln 2=0.67$. The strain rate was calculated by taking into account the applied strain $(\gamma)$, the roller diameter $(D)$, the gap between rollers $(h)$, and the speed $(v)$, using the equation $^{20}$

$$
\dot{\gamma}=\frac{v \gamma}{L}
$$

where

$$
L=\left(\frac{D h}{2}\right)^{1 / 2}
$$

$L$ is the effective gauge length. All the rolling was performed at a strain rate of $1 \mathrm{~s}^{-1}$. Care was taken to keep the laminates flat and the rolling process under a plane-strain condition; i.e., the laminates were kept at the same width and were not allowed to strain in the axial direction of the rollers. To prevent sticking during rolling, the doughs were wrapped in a plastic sheet.

Three sets of samples were made, with varying salt concentrations: set A, which contained $2.2 \mathrm{M} \mathrm{Al}_{2} \mathrm{O}_{3}$ and $3.3 \mathrm{M} \mathrm{Ce}-\mathrm{TZP}$; set $\mathrm{B}$, which contained $2.2 \mathrm{M} \mathrm{Al}_{2} \mathrm{O}_{3}$ and $2.2 \mathrm{M} \mathrm{Ce}-\mathrm{TZP}$; and set $\mathrm{C}$, which contained $2.2 \mathrm{M} \mathrm{Al}{ }_{2} \mathrm{O}_{3}$ and $3.8 M$ Ce-TZP. The salt concentrations were chosen so that the yield stress of the CeTZP slurry could vary from being the same as (set A), lower than (set B), or higher than (set C) that of the $\mathrm{Al}_{2} \mathrm{O}_{3}$ slurry; this point will become clearer later in this paper.

\section{(5) Sintering and Characterization}

The laminates were dried at room temperature and atmospheric pressure and then fired in air at $1600^{\circ} \mathrm{C}$ for $3 \mathrm{~h}$. A rate

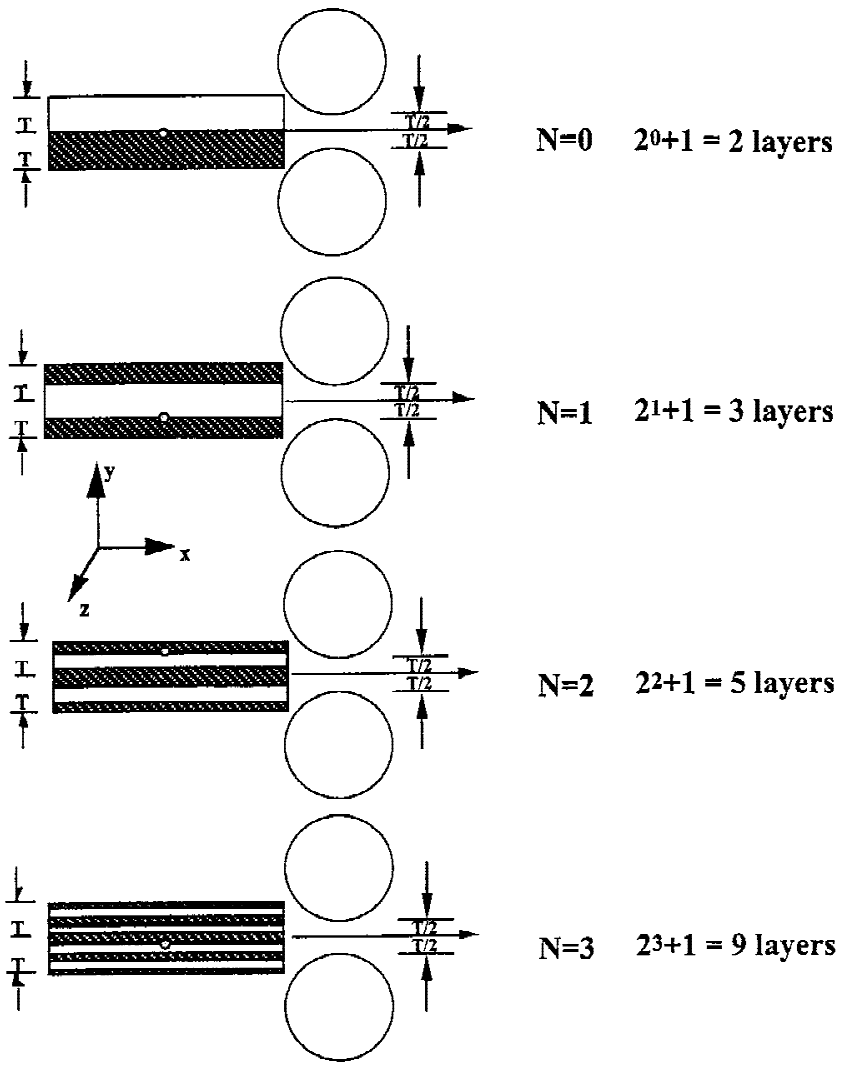

Fig. 1. Schematic of the rolling process. After initial rolling (to shape the doughs into tapes of uniform thickness), the $\mathrm{Al}_{2} \mathrm{O}_{3}$ and Ce-TZP tapes are placed on top of each other and rolled again. By keeping the gap between the rollers the same as the original tape thickness and by repeated folding and rolling, increments of $100 \%$ strain were obtained. The small circles in the laminates mark the movement of one material element that is initially at the center. (Assume folding over the top surface.) The coordinates also are defined in the inset.

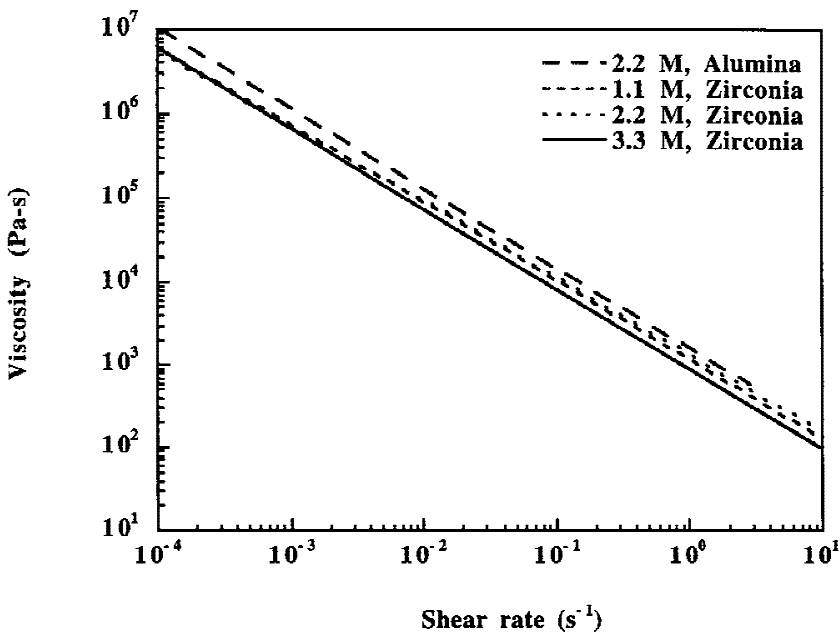

Fig. 2. Viscosity as a function of shear rate for $\mathrm{Al}_{2} \mathrm{O}_{3}$ and Ce-TZP slurries at pH 2 and a solids loading of 64 vol\%.

of $5^{\circ} \mathrm{C} / \mathrm{min}$ was used during heating and cooling. Microstructure studies were performed using scanning electron microscopy (SEM) on sectioned and polished surfaces. To determine the grain size of the composite, the samples were thermally etched at $1500^{\circ} \mathrm{C}$ for $6 \mathrm{~min}$. The grain size in the SEM micrographs then was analyzed using a public-domain NIH Image ${ }^{21}$ program and assuming spherical grains. 


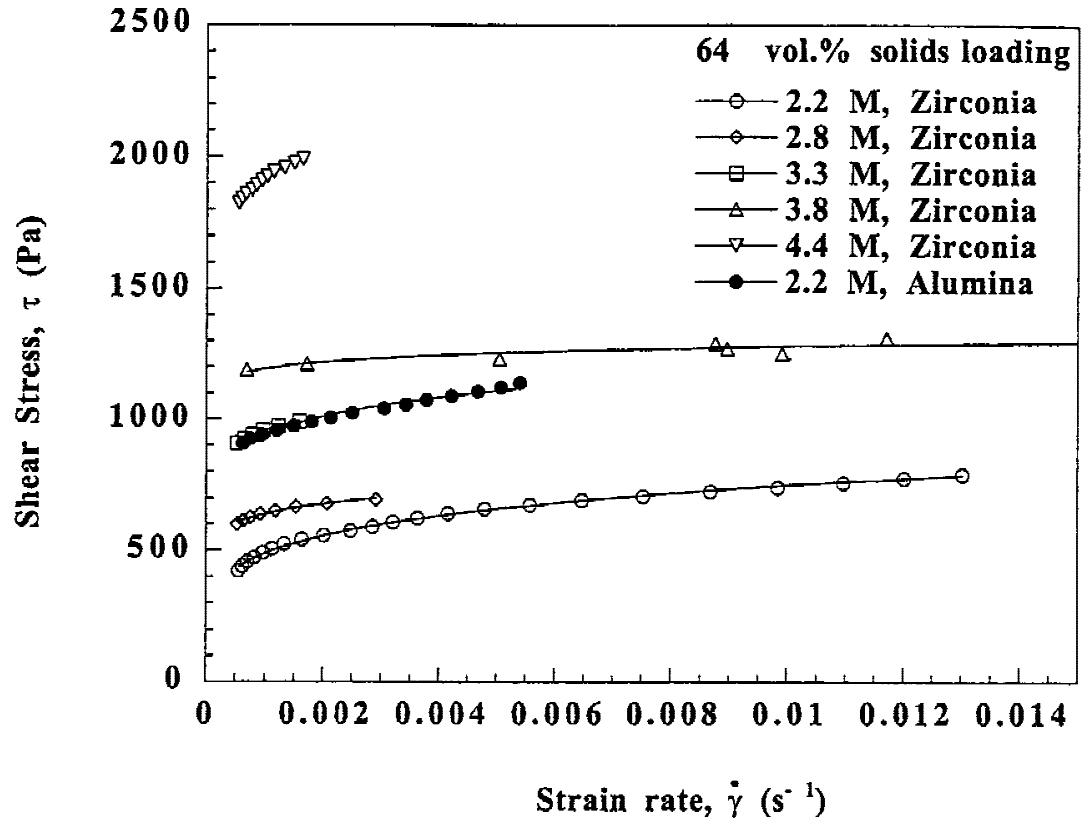

Fig. 3. Shear-stress-strain-rate curves for $\mathrm{Al}_{2} \mathrm{O}_{3}$ and Ce-TZP slurries at $\mathrm{pH} 2$ and a solids loading of 64 vol\% at various salt concentrations.

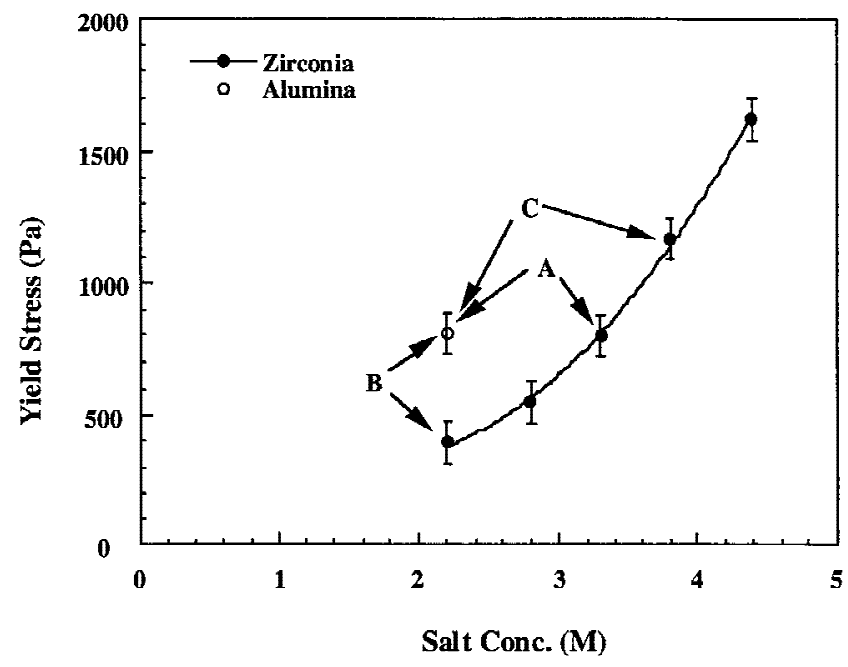

Fig. 4. Yield stress of Ce-TZP slurry, plotted as a function of the $\mathrm{NH}_{4} \mathrm{NO}_{3}$ salt concentration (c); the yield stress of $\mathrm{Al}_{2} \mathrm{O}_{3}$ also is plotted for comparison. Three sets of samples are studied in this work: A, which is composed of $2.2 M \mathrm{Al}_{2} \mathrm{O}_{3}$ and $3.3 M$ Ce-TZP; $\mathrm{B}$, which is composed of $2.2 \mathrm{M} \mathrm{Al}_{2} \mathrm{O}_{3}$ and $2.2 \mathrm{M} \mathrm{Ce}-\mathrm{TZP}$; and $\mathrm{C}$, which is composed of $2.2 \mathrm{M} \mathrm{Al}_{2} \mathrm{O}_{3}$ and $3.8 M$ Ce-TZP. Yield-stress data for Ce-TZP scales as the square of the salt concentration $\left(c^{2}\right)$.

Measurements of the geometrical features were made on the $z$-direction cross sections (see Fig. 1). A straight line was drawn perpendicular to the layers through the micrograph and the intersections between the line and the layer boundaries were counted. The average layer thickness was determined using this procedure. To determine the continuity of the $\mathrm{Al}_{2} \mathrm{O}_{3}$ and Ce-TZP layers, which eventually lost their continuity by phase mixing after repeated rolling, a montage of several micrographs was constructed and the aspect ratio of the continuous region was measured using the following procedure:

(1) The length along the $x$-direction of each continuous region for a phase was measured. For samples with a low number of foldings (less than six), the maximum length of the layers was set as the distance from one end of the montage to the other, although most layers are extended beyond the distance.
(2) Then, the average length of the continuous region was calculated for each phase.

(3) The aspect ratio was calculated from the ratio of the average length of the region and the thickness of the layers. For samples with a low number of foldings (less than six), the measurement technique in step (1) underestimated the length, giving an aspect ratio that was lower than actual.

\section{Results}

\section{(1) Drying and Green Density}

The solids loading of the dough before drying was adjusted to $64 \mathrm{vol} \%$ for both $\mathrm{Al}_{2} \mathrm{O}_{3}$ and $\mathrm{Ce}$-TZP doughs. The solids loading can be adjusted by varying the $\mathrm{pH}$ and the salt concentration of the dough. After drying, no cracks were detected on the surface of the rolled composites. Dimensional measurements that were made on the green samples before and after drying resulted in the same values. Therefore, the green density obtained after drying also was $64 \%$. Such a high green density makes sintering of these composites easier.

\section{(2) Rheology}

Figure 2 shows the viscosity versus the shear rate of $\mathrm{Al}_{2} \mathrm{O}_{3}$ and Ce-TZP doughs at a solids loading of 64 vol\%. Shearthinning behavior, with decreasing viscosity $(\eta)$ at increasing strain rate $\dot{\gamma}$, is observed for both cases. Furthermore, the data seem to fit a power law over five orders of magnitude, following a $\eta \propto \dot{\gamma}^{-1}$ relation for all salt concentrations. Because $\eta=$ $\tau / \dot{\gamma}$ in our measurement, this result implies a relatively constant shear stress. From these data, we also infer that the viscosity of these doughs at the rolling condition $\left(\dot{\gamma}=1 \mathrm{~s}^{-1}\right)$ is $\sim 10^{3} \mathrm{~Pa} \cdot \mathrm{s}$, which is approximately the consistency of a pasta dough. In comparison, the viscosity of water at room temperature is $10^{-3}$ $\mathrm{Pa} \cdot \mathrm{s}$. Increasing the salt content at the same $\mathrm{pH}$ and solids loading had no appreciable effect on the shear-thinning behavior for Ce-TZP.

Figure 3 shows some shear-stress-shear-strain-rate curves for $\mathrm{Al}_{2} \mathrm{O}_{3}$ and $\mathrm{Ce}-\mathrm{TZP}$ doughs at $\mathrm{pH} 2$ and a solids loading of $64 \mathrm{vol} \%$. Various salt concentrations were used for Ce-TZP. Although the shear stress is relatively flat over a range of $0.005-0.01 \mathrm{~s}^{-1}$, no data were obtained below the yield stress, because no strain could be detected below the yield stress. Also, the stress level for $\mathrm{Al}_{2} \mathrm{O}_{3}$ lies in the middle, with $\mathrm{Ce}-\mathrm{TZP}$ 


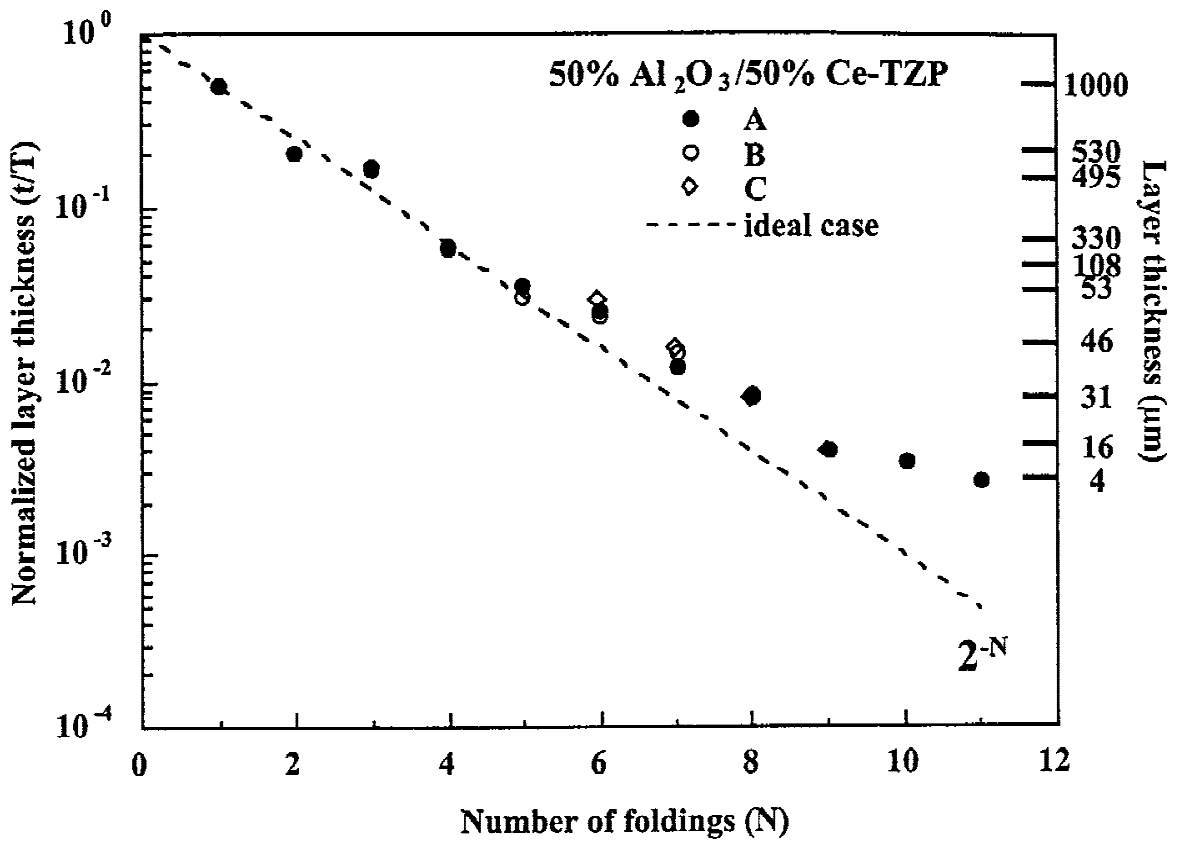

Fig. 5. Scaling of the normalized layer thickness ( $t / T$, where $t$ is the layer thickness and $T$ is the sample thickness), relative to the number of foldings $N$. Broken line represents the ideal case.

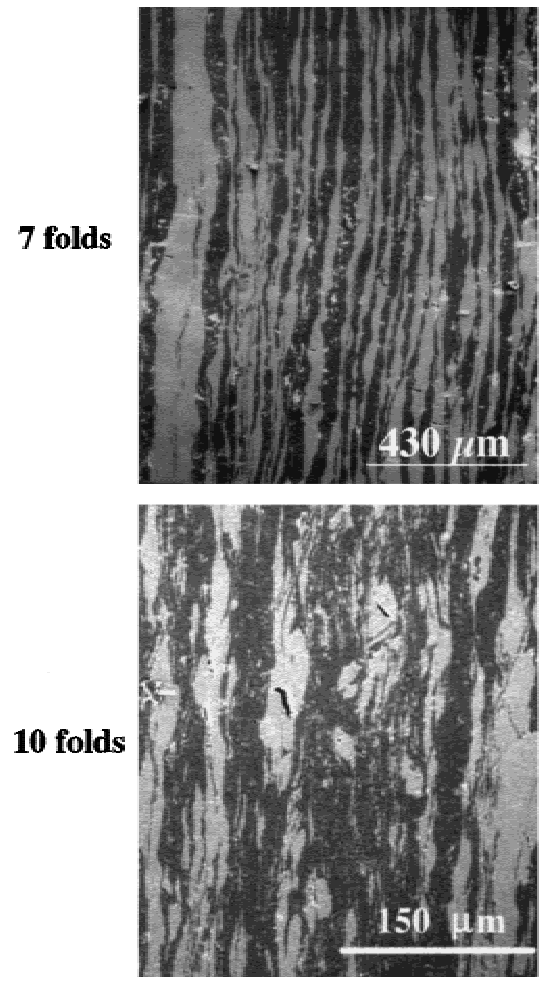

(a)
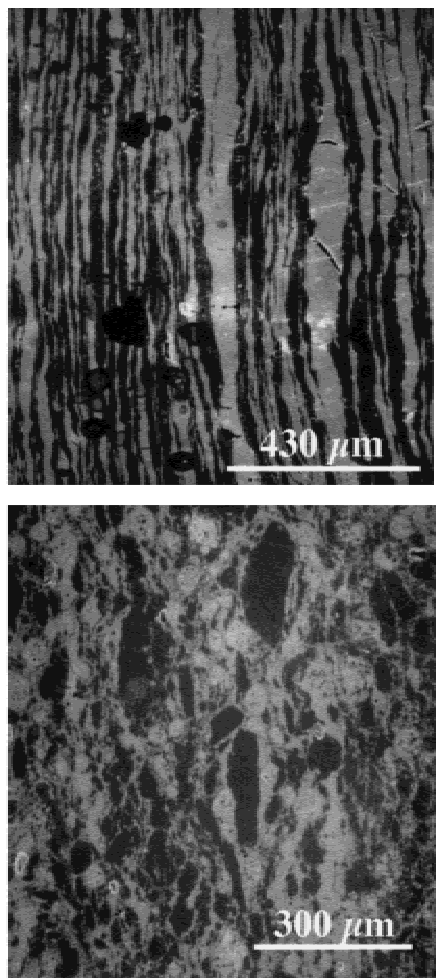

(b)
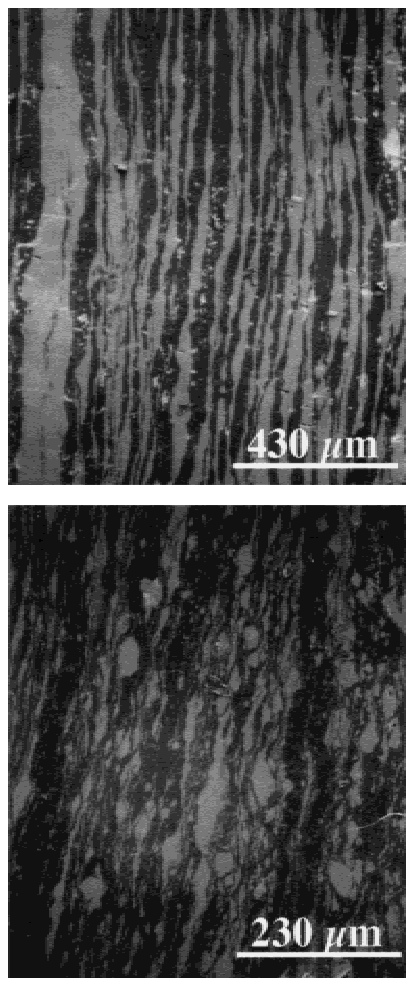

(c)

Fig. 6. Microstructures after seven and ten foldings for (a) sample $\mathrm{A}$, (b) sample $\mathrm{B}$, and (c) sample $\mathrm{C}$. $\mathrm{Al}_{2} \mathrm{O}_{3}$ has a darker contrast, and Ce-TZP has a lighter contrast.

being either harder or softer, depending on the salt content. Using Eq. (1), we determined the yield strength, which is shown in Fig. 4. Figure 4 shows that the yield stress of Ce-TZP increases as the salt concentration increases. Comparing the yield stress of $\mathrm{Ce}-\mathrm{TZP}$ with that of $\mathrm{Al}_{2} \mathrm{O}_{3}$, we can verify that, in sample set $\mathrm{A}$, the yield stresses of the two doughs match; in sample set $\mathrm{B}$, the $\mathrm{Al}_{2} \mathrm{O}_{3}$ dough has a higher yield stress, and, in sample set $\mathrm{C}$, the Ce-TZP dough has a higher yield stress.

\section{(3) Microstructure}

(A) Scaling of Layer Thickness: Ideally, the number of layers increases in a $2^{N}+1$ manner after $N$ foldings and roll- 

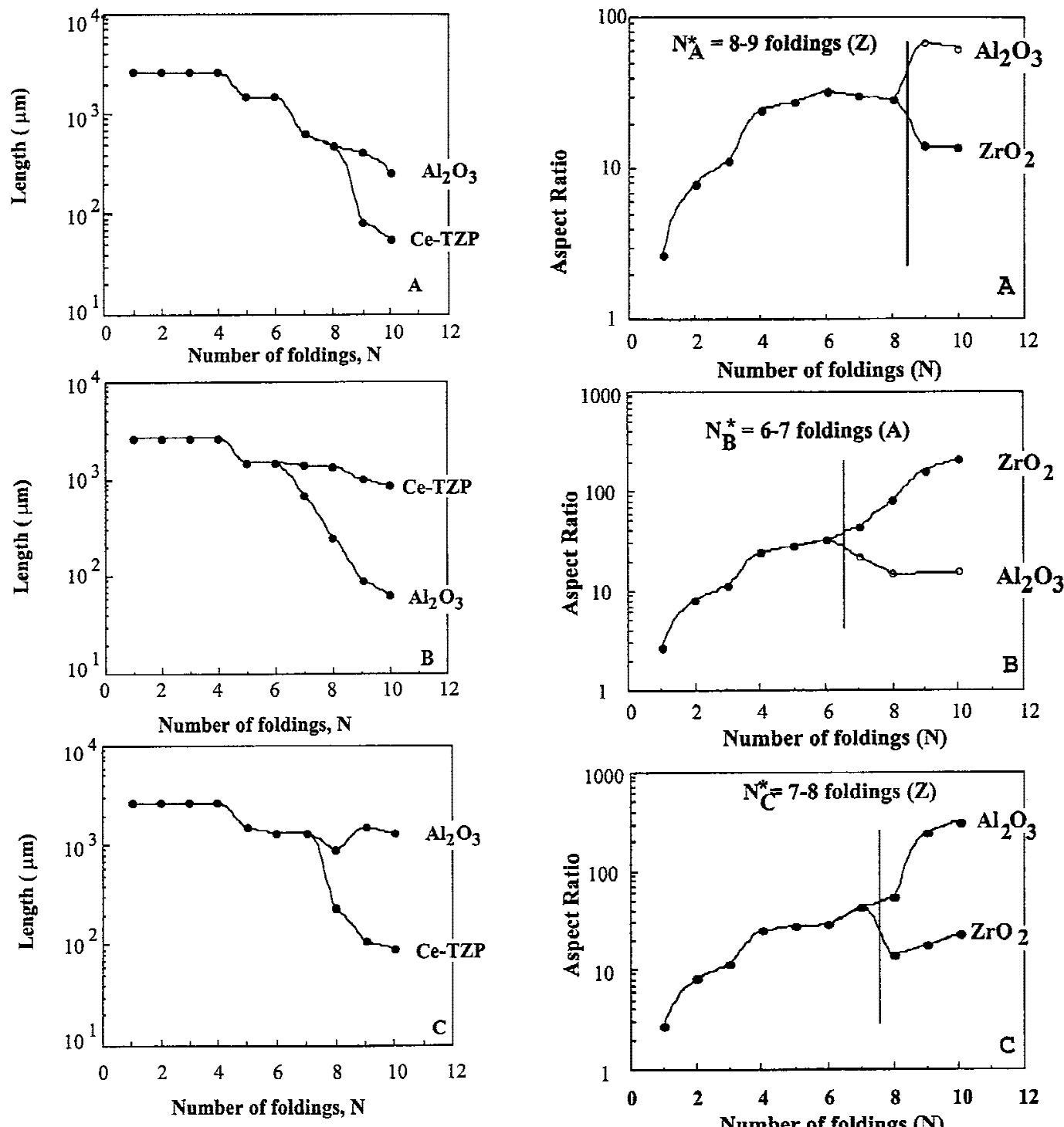

(a)

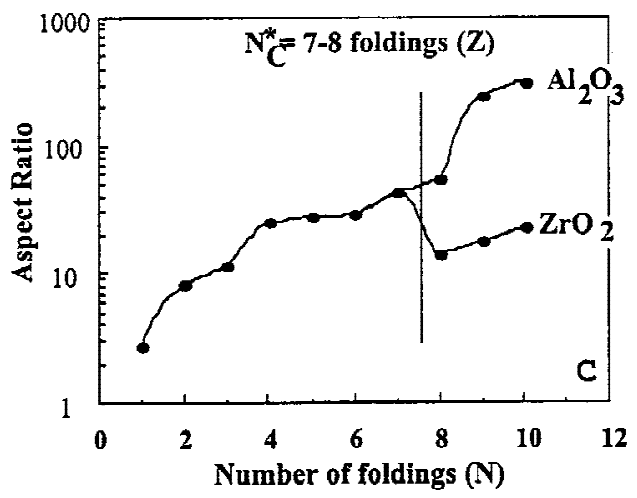

(b)

Fig. 7. (a) Length of layers and (b) aspect ratio for samples A, B, and C, plotted as a function of the number of foldings $N$. In Fig. 7(b), note that the microstructure transition occurs at $N=8-9$ for sample A, $N=6-7$ for sample $\mathrm{B}$, and $N=7-8$ for sample C.

ings (Fig. 1). Thus, the average layer thickness is expected to decrease rapidly. The average layer thickness decreases from 1 $\mathrm{mm}$ to $\sim 4 \mu \mathrm{m}$ in eleven foldings. The average normalized layer thickness, $t / T$ (where $t$ is the layer thickness, as determined by the linear intercept method, and $T$ is the sample thickness), is plotted in Fig. 5 as a function of number of foldings $N$. The relationship between the normalized thickness and the number of foldings is expected to follow the relation

$$
\frac{t}{T}=2^{-N}
$$

except for the outermost layer, which has a thickness of $t / 2$. This expected behavior is shown in Fig. 5 as the dotted line and is obeyed up to approximately five foldings. Beyond that point, the thickness reduction becomes slower because of flow instability.

(B) Instability in Rolling: Figure 6 shows the microstructure of sample sets $\mathrm{A}, \mathrm{B}$, and $\mathrm{C}$, as a function of the number of foldings. The interface between $\mathrm{Al}_{2} \mathrm{O}_{3}$ and $\mathrm{Ce}-\mathrm{TZP}$ is always wavy and the layer thickness is not uniform, although the average thickness does follow a simple scaling relationship, as shown in Fig. 5. Some of the waviness and thickness variation may be due to the deformation gradient at the surface due to rolling friction. However, systematic differences also were present between different samples sets for which the flow stresses of the constituent doughs varied. We observed that the flat interface between doughs was unstable under deformation, and waviness resulted. Eventually, when the perturbation was on the order of the layer thickness, the laminate structure broke down. This result can be observed by comparing the microstructure after seven and ten foldings in Fig. 6(b). In the former case, a layer structure is maintained, whereas in the latter case, the alumina phase (the darker regions) seems to be enclosed in islands. A similar breakdown of the layer structure is observed in Figs. 6(a) and (c), both of which have the zirconia phase (lighter) enclosed in islands.

To quantify this development, the length and aspect ratios of the phase region (layers) are plotted as a function of $N$ in Figs. 7(a) and (b). If the laminates are continually rolled to make the layers thinner, we expect both the length and the aspect ratio to increase. In reality, however, a continuous decrease of the 
length is observed for both phases in all cases. (The initially constant length is set as the length of the montage and is an artifact.) This observation means that the layers are being broken down during rolling. A continuous increase in the aspect ratio indeed is observed for $\mathrm{Al}_{2} \mathrm{O}_{3}$ in sample $\mathrm{A}, \mathrm{Ce}-\mathrm{TZP}$ in sample $\mathrm{B}$, and $\mathrm{Al}_{2} \mathrm{O}_{3}$ in sample $\mathrm{C}$; however, the aspect ratio abruptly decreases at a certain point when the enclosed phase forms. This condition is the case for Ce-TZP in sample A, $\mathrm{Al}_{2} \mathrm{O}_{3}$ in sample $\mathrm{B}$, and $\mathrm{Ce}-\mathrm{TZP}$ in sample $\mathrm{C}$. The critical number of foldings-when the cellular structure starts to form - may be defined as that for which the aspect ratio begins to decrease significantly. This number is $N_{\mathrm{A}}^{*}=8-9(\mathrm{Ce}-\mathrm{TZP})$ in sample $\mathrm{A}, N_{\mathrm{B}}^{*}=6-7\left(\mathrm{Al}_{2} \mathrm{O}_{3}\right)$ in sample $\mathrm{B}$, and $N_{\mathrm{C}}^{*}=7-8$ $(\mathrm{Ce}-\mathrm{TZP})$ in sample $\mathrm{C}$. Here, the material that is given in parentheses is the enclosed phase. It is interesting to note that, although the breakdown in aspect ratio in sample A occurs at $N_{\mathrm{A}}^{*}=8-9$, the aspect ratio stabilizes and starts to decrease after six foldings. Thus, the layered microstructure starts to gradually transform to a cellular microstructure, even before reaching the critical number of foldings for the transition. This gradual change may be regarded as a pretransition beginning at approximately six foldings.

The phase that shows a decreasing aspect ratio and becomes isolated in the micrographs is rheologically harder. For example, in sample $\mathrm{B}$, the $\mathrm{Al}_{2} \mathrm{O}_{3}$ dough has a higher yield stress than does the $\mathrm{Ce}-\mathrm{TZP}$ dough. Likewise, in sample $\mathrm{C}$, the $\mathrm{Ce}$ TZP dough has a higher yield stress than that of the $\mathrm{Al}_{2} \mathrm{O}_{3}$ dough. The case for sample $\mathrm{A}$ is not as clear-cut. According to Fig. 4, Ce-TZP and $\mathrm{Al}_{2} \mathrm{O}_{3}$ have the same yield stress. However, the microstructure shown in Fig. 6(a) and the aspect ratio shown in Fig. 7(a) indicate that the Ce-TZP dough is the isolated phase, which suggests that it also is the rheologically harder phase. The rolling and folding very likely causes changes in the surface characteristics of $\mathrm{ZrO}_{2}$ and $\mathrm{Al}_{2} \mathrm{O}_{3}$, as well as in their rheology. ${ }^{22}$ However, the details of these changes were not investigated.

For a rolled composite with a high aspect ratio of phase regions, the interfacial areas (between the two phases) per unit volume scales with the reciprocal of the "layer" thickness. According to Fig. 5, the same layer thickness is obtained in all the samples after the same number of foldings. Therefore, there is no significant difference in the interfacial area density in different samples. Then, only the geometric connectivity is different. This point will become relevant when we discuss the properties of this family of composites in a later paper. ${ }^{18}$

Lastly, we note that the microstructure in the cellular state is similar in cross sections in both the $x$ - and $z$-directions. This microstructure is shown in Fig. 8 for sample $C$ that has been folded nine times. This result implies that the instability propagates throughout the entire interface. Later, however, we will show that the strengths are different in the two directions. ${ }^{18}$ Thus, despite the similarity in the microstructure, the rolled cellular composite is actually orthotropic.

(C) Grain Size, Porosity, and Cracks: Etched microstructures of sample B are shown in Fig. 9. Note that the interface between the $\mathrm{Al}_{2} \mathrm{O}_{3}$ and Ce-TZP is devoid of any delamination or pores. In addition, there is evidence of mixing of the Ce-TZP (bright spots) in $\mathrm{Al}_{2} \mathrm{O}_{3}$ (dark matrix) presumably during rolling. Some stringers of $\mathrm{Al}_{2} \mathrm{O}_{3}$ grains in the Ce-TZP layers, and vice versa, also are commonly observed.

The grain sizes measured for Ce-TZP and $\mathrm{Al}_{2} \mathrm{O}_{3}$ are shown as a function of the number of foldings $N$ for samples $\mathrm{A}, \mathrm{B}$, and $\mathrm{C}$ in Fig. 10. The grain size for both phases generally decreased as $N$ increased, although the grain size of Ce-TZP is relatively independent of microstructure. This observation is presumably due to the lower grain-boundary mobility that has been reported for TZP materials. ${ }^{23}$ Comparing the grain size of $\mathrm{Al}_{2} \mathrm{O}_{3}$ in samples $\mathrm{A}$ and $\mathrm{B}$ that have been folded nine times, we see a smaller grain size when $\mathrm{Al}_{2} \mathrm{O}_{3}$ is the enclosed phase (material $\mathrm{B}$ ) in the cellular microstructure. Sample $\mathrm{C}$ is intermediate between sample $\mathrm{A}$ and $\mathrm{B}$, relative to the order of hardness ratio (Fig. 4), and its $\mathrm{Al}_{2} \mathrm{O}_{3}$ grain size also is between that of samples $\mathrm{A}$ and $\mathrm{B}$.

Although some porosity is evident in the micrographs, most

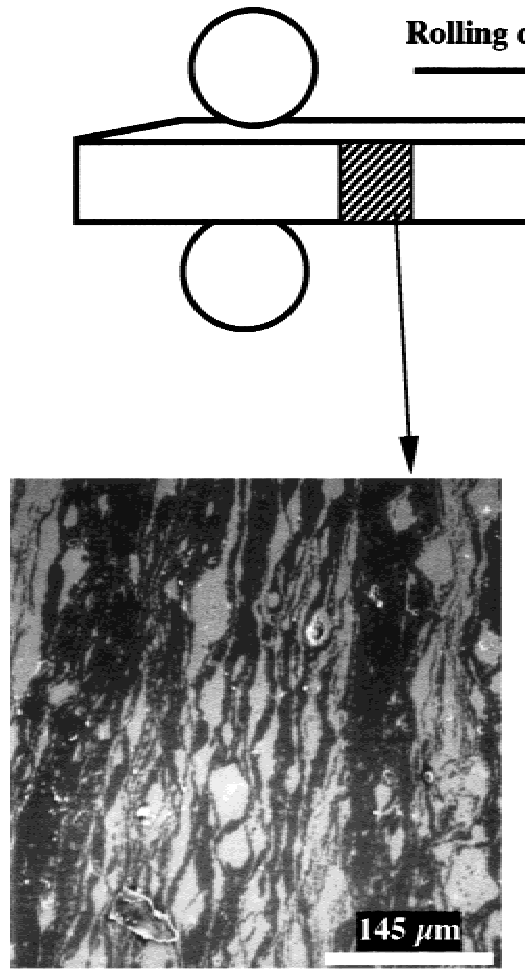

(a)

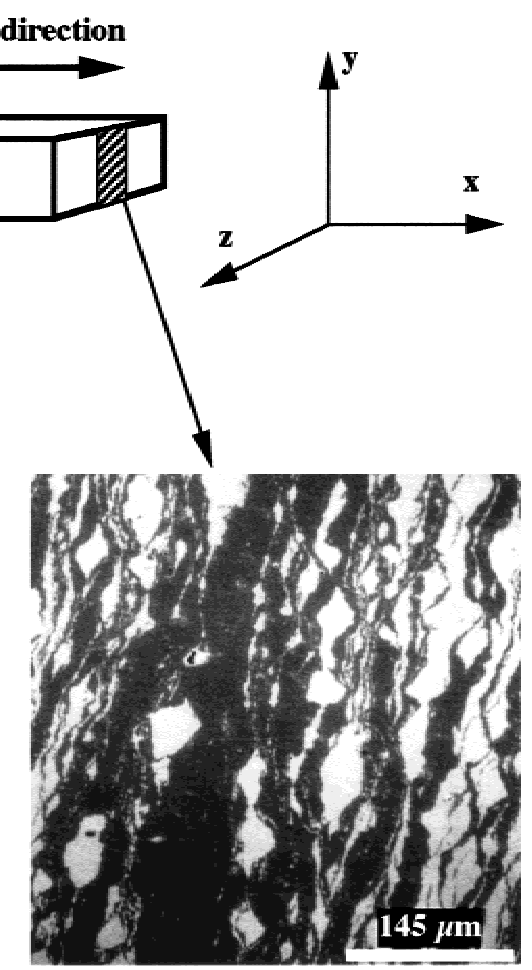

(b)

Fig. 8. Microstructure of sample $\mathrm{C}$ folded nine times (a) parallel and (b) perpendicular to the rolling direction. Notice that there is no significant difference between the two microstructures, indicating that the instability during rolling is diffuse in nature. Rolling direction is vertical. 

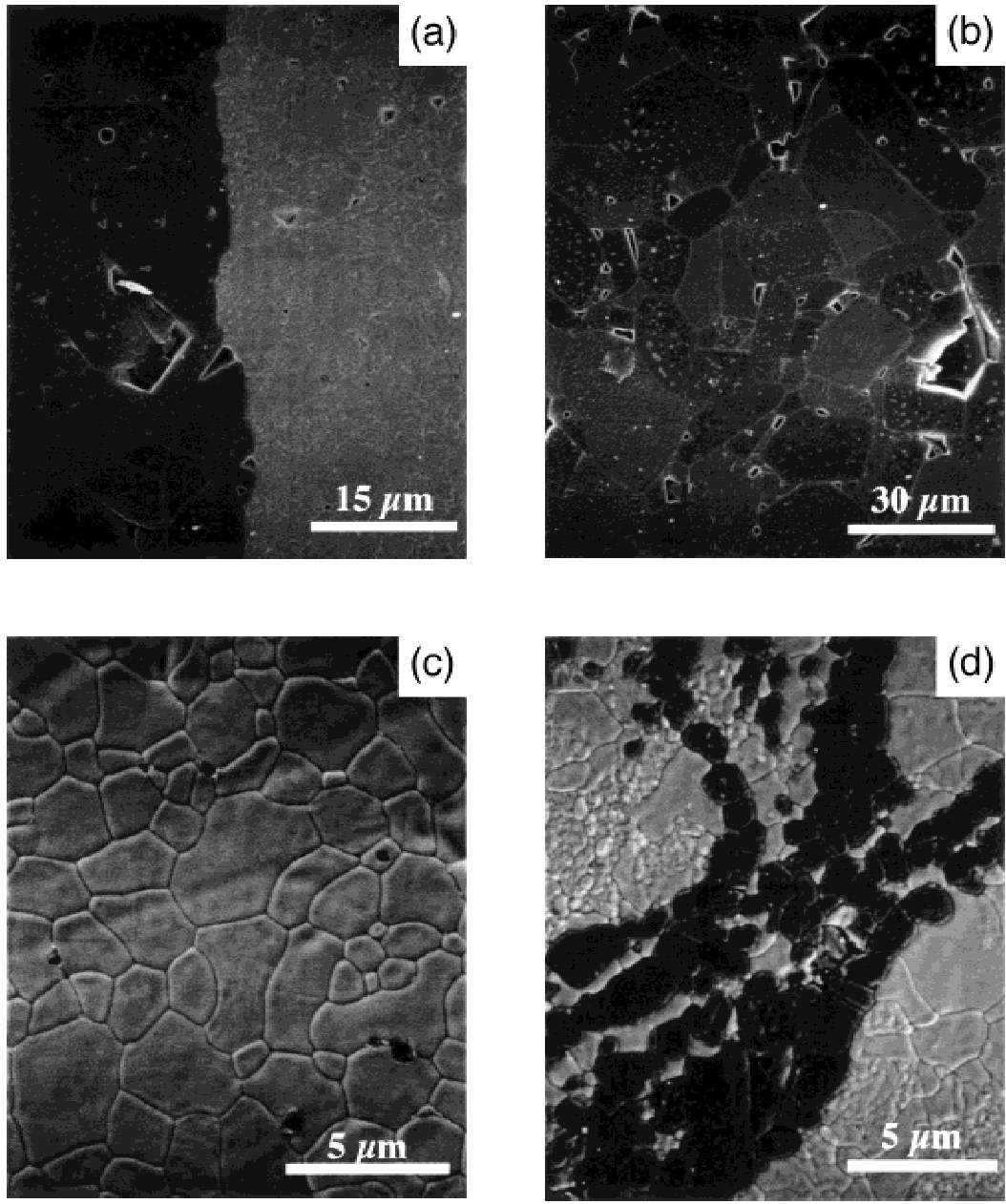

Fig. 9. (a) Layer microstructure in sample B folded four times, showing good interfacial adhesion. Phase mixing in this sample is shown by Fig. 9(b), where Ce-TZP appears as white spots in $\mathrm{Al}_{2} \mathrm{O}_{3}$ and Fig. 9(c), where $\mathrm{Al}_{2} \mathrm{O}_{3}$ appears as dark spots in Ce-TZP. Figure 9(d) shows the cellular microstructure in sample B folded nine times, showing phase mixing; the rolling direction is vertical.

of the pores were artifacts from the polishing step that caused grain pullout. The density of the composites is actually quite high: $>98 \%$ of the theoretical value. Some thermal cracks also were present in the Ce-TZP layers. However, the cracks disappeared when the layer thickness was less than a critical value. No cracks were evident in $\mathrm{Al}_{2} \mathrm{O}_{3}$. These aspects will be described in more detail in the second paper of this series. ${ }^{17}$

\section{Discussion}

\section{(1) Rheology and Cohesion}

The doughs that are studied here have a high solids loading (64 vol\%), exhibit shear-thinning behavior, and are plastic in nature. At such a high solids loading, the particles are in contact with each other and can be held together via capillary action. ${ }^{24-31}$ Essentially, the liquid will form a meniscus on the liquid/air/particle interface at the exterior surface to pull in the particles, which stack against each other and transmit tractions to support the capillary forces. Such capillary pressure is on the order of $2 \gamma / R$, where $\gamma$ is the surface tension of the liquid and $R$ is the radius of curvature of the meniscus. Scaling considerations then allow us to assume $R$ to be proportional to the particle size. For a radius of $0.3 \mu \mathrm{m}$ and the bulk value for $\gamma(72.14 \mathrm{mN} / \mathrm{m})$ for water at room temperature, ${ }^{28}$ we estimate a pressure of $0.48 \mathrm{MPa}$, which is a much higher stress than that used in rolling the doughs. In reality, this pressure could be even higher if the surface tension of water increases dramatically as the surfaces come closer. ${ }^{28-30}$ In addition, the ions that are present in the slurry could diffuse and form a "bridge" in the liquid between particles, changing the adhesion between the surfaces. ${ }^{28}$ Thus, this stress is obviously a source of cohesion and ductility of the doughs in our work. Soil mechanics considerations ${ }^{32,33}$ also credit the capillary forces as the agent that holds the particle-water mass intact. In our system, the high solids loading and the small particle size make these forces especially important.

Another source of cohesion and plasticity is the attractive forces between particles, via van der Waals interaction. ${ }^{14-16}$ Current understanding of coagulated slurries ${ }^{31}$ suggests that the floc structure is strongly dependent on the magnitude of the attractive forces, relative to the yield stress of the slurry, and that a compact floc structure is possible only if the attractive forces are weak enough to allow particle rearrangement at the yield stress. Given the very high solids loading that is obtained in pressure casting in our study, the above-described condition must have been met. Thus, the attractive stress is likely to be on the order of the yield stress $(\sim 500-1000 \mathrm{~Pa})$. This stress is a much smaller cohesive stress than the capillary stress that was estimated previously and would seem to be of secondary importance. Although the shear-thinning behavior and the ability of the dough to "set" when no deformation forces is applied do suggest that the slurry has a weak attractive force that is responsible for coagulation, ${ }^{14}$ such weak attraction alone cannot be the source of the good cohesion of our doughs.

Rheological data of our doughs are consistent with that reported by Chang et al. ${ }^{15}$ and Yanez et al. ${ }^{16}$ for slurries of comparable compositions. These studies include shear thinning 
(a)

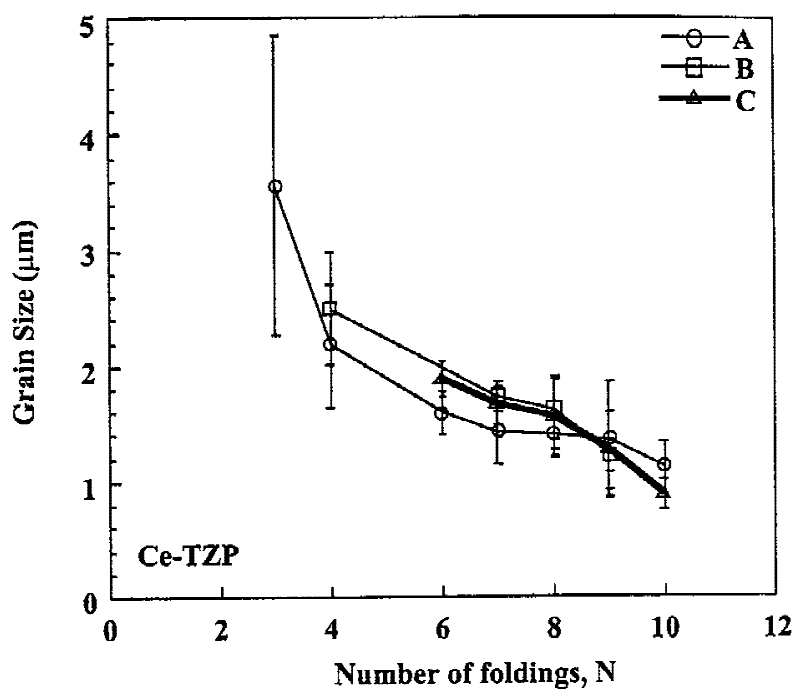

(b)

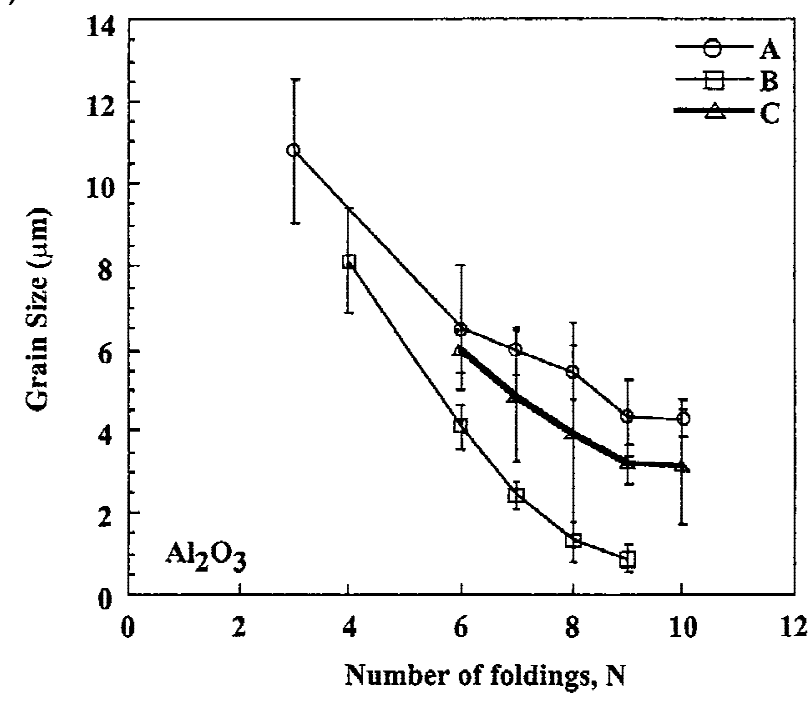

Fig. 10. Grain size of (a) Ce-TZP and (b) $\mathrm{Al}_{2} \mathrm{O}_{3}$ in samples $\mathrm{A}, \mathrm{B}$, and $\mathrm{C}$, as a function of the number of foldings $N$.

and the dependence of the yield stress on the solids loading and the salt concentration. (However, our data were taken at a much higher solids loading.) Because matching the green densities of the layers is of prime importance for the sintering of composites, the yield stress in this work was controlled only by the salt concentration, as shown in Fig. 4. At the high solids loading that we used, the yield stress of the Ce-TZP slurry scales with the salt concentration as $c^{2}$, according to Fig. 4, which is a stronger dependence than that observed in the $\mathrm{Al}_{2} \mathrm{O}_{3}$ slurries. ${ }^{16}$ The dependence of the salt concentration on the yield stress can be qualitatively understood as follows. As the salt concentration increases, the electrostatic repulsion between particles is more fully screened, which leaves only the van der Waals attraction to act and affect the yield stress. However, the details of the mechanisms are not fully understood, given the very high salt concentration and the very small screening distance in these slurries.

\section{(2) Microstructure Evolution during Rolling}

The salient observations and results regarding rolling instability are summarized as follows:

(1) The interface between the alumina and zirconia was wavy after rolling.
(2) The aspect ratio of the harder layers decreased discontinuously beyond a certain strain.

(3) The layered microstructure was broken down into a cellular geometry, where the phase with a higher yield stress is enclosed within the phase with a lower yield stress.

(4) Samples with a higher yield-stress difference between phases have a lower critical strain for layer breakdown.

The above-described results strongly suggest that an internal deformation gradient exists in rolling and that the flat interface between layers with different yield stresses is not stable under rolling conditions. Rolling is a deformation processing technique in which the sheet material is stretched in (unbalanced) biaxial tension under a superimposed hydrostatic pressure. ${ }^{20}$ Instability under somewhat similar deformation conditions has been observed in the rolling of clad metals ${ }^{34,35}$ and the coextrusion of polymers. ${ }^{36}$ When a layered composite is rolled, the flat interface between phases of different flow stress may be expected to be similarly unstable.

The essence of this instability can be understood by referring to Fig. 11. With a flat interface, the deformation load for a bimaterial in the length direction is given by $\sigma_{1} A_{1}+\sigma_{2} A_{2}$, where $\sigma_{1}$ and $\sigma_{2}$ are the flow stresses of layers 1 and 2 and $A_{1}$ and $A_{2}$ are the respective cross-sectional areas. By introducing a perturbation of amplitude $\delta A$ at the interface, the deformation load changes to $\sigma_{1}\left(A_{1}-\delta A\right)+\sigma_{2}\left(A_{2}-\delta A\right)+2 \sigma_{1-2} \delta A$, where $\sigma_{1-2}$ is the flow stress of the perturbed region. For the idealized configuration in Fig. 11, in which the two materials are stacked in series, $\sigma_{1-2}$ can be approximated by $\min \left(\sigma_{1}, \sigma_{2}\right)$. Therefore, the deformation load is less than $\sigma_{1} A_{1}+\sigma_{2} A_{2}$. The upper bound (isostrain) estimate of $\sigma_{1-2}$ also is known and is given by the volume average of $\sigma_{1}$ and $\sigma_{2}$ : i.e., $\left(\sigma_{1}+\sigma_{2}\right) / 2$, which applies when the two materials are stacked in parallel. In this limit, the deformation load reverts to $\sigma_{1} A_{1}+\sigma_{2} A_{2}$. For a more general case between the above-mentioned two limits, the deformation resistance is between the two estimates and, thus, is always reduced by the introduction of an interface perturbation. This observation is the reason why the interface perturbation originally develops. Ultimately, the tendency is to have the harder phase enclosed in a matrix of the softer phase, because the total deformation resistance of this configuration is more similar to that of the softer phase and is the lowest possible resistance for a bimaterial composite of any configuration.

We will postpone the mathematical analysis of the instability criterion until a future publication. However, it is intuitively obvious from the above-given argument that interface instability leads to thinning of the harder phase and bulging of the softer phase, regardless of the loading/straining mode. When a strip that consists of suspensions of different flow stresses is rolled, the interface instability is manifest as a distortion of the flat interface to a wavy interface. Eventually, when the amplitude of this perturbation is equal to half of the thickness of the layer, the layers begin to break down, with the harder material being entrapped inside the softer material. This phenomenon results in a sudden decrease in the aspect ratio of the harder

(a)

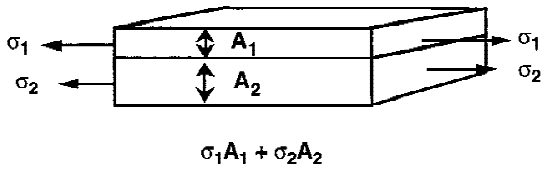

(b)

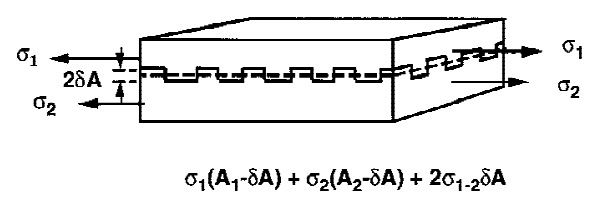

Fig. 11. Schematic of rolling of a bilayer; in this depiction, the deformation force required for the flat interface (Fig. 11(a)) is higher than that required for the perturbed interface (Fig. 11(b)). 
phase as observed. The instability is expected to be more pronounced as the disparity in flow stress increases, as also is verified by our observations. Note, however, that the strains required to reach the phase breakdown are "huge" and require six to eight foldings and rolling. This determination corresponds to a strain of $2^{6}$, or $6400 \%$ (true strain of 4.16 ), to $2^{8}$, or $25600 \%$ (true strain of 5.55). Such large strains are not typical for other deformation processing operations but can easily be achieved using repeated folding and rolling.

A large variation of layer thickness was observed sporadically in our samples, as is apparent from the microstructures shown in Fig. 6. This variation begins to emerge well before the transition from a laminate to a cellular structure. We recently have performed compression experiments using ceramic tapes that contained binders and plasticizers of different deformation resistance. ${ }^{37}$ In such experiments, large strains were attained but folding was avoided; yet, we observed the same phenomenon. Thus, the variation in layer thickness is a manifestation of the interface instability and is not due to folding. Indeed, the microstructure development in these polymercontaining materials was very similar to that described previously, which provides strong support that the interface instability is inherent in deforming bimaterial laminates of different deformation resistance.

\section{Conclusions}

(1) Laminate composite fabrication via repeated rolling and folding has been demonstrated using aqueous slurries of ceramic powders without any plasticizers or binders. Crackfree $\mathrm{Al}_{2} \mathrm{O}_{3} / \mathrm{Ce}$-TZP composites with a layer thickness of 4-60 $\mu \mathrm{m}$ have been obtained.

(2) The interface that separates two layers with different flow properties is unstable under large strain deformation. This instability is manifested as interface waviness in rolling.

(3) When the amplitude of the perturbation approaches the layer thickness, the structure breaks down into a cellular structure. The harder phase is encased in the softer phase.

(4) The instability depends primarily on the disparity of the yield stress of the layers. This principle can be exploited to obtain layered materials (by matching the yield stress of the slurries) or cellular materials with the desired encased phase.

\section{References}

${ }^{1}$ W. J. Clegg, K. Kendall, N. McN.Alford, T. W. Button, and J. D. Birchall, "A Simple Way to Make Tough Ceramics," Nature (London), 347, 455-57 (1990).

${ }^{2}$ W. J. Clegg, "The Fabrication and Failure of Laminar Ceramic Composites," Acta Metall. Mater., 40 [11] 3085-93 (1992).

${ }^{3}$ J. Requena, R. Moreno, and J. S. Moya, "Alumina and Alumina/Zirconia Multilayer Composites Obtained by Slip Casting," J. Am. Ceram. Soc., 72 [8] 1511-13 (1989).

${ }^{4}$ D. B. Marshall, J. J. Ratto, and F. F. Lange, "Enhanced Fracture Toughness in Layered Microcomposites of $\mathrm{Ce}-\mathrm{ZrO}_{2}$ and $\mathrm{Al}_{2} \mathrm{O}_{3}$, , J. Am. Ceram. Soc., 74 [12] 2979-87 (1991).

${ }^{5}$ D. B. Marshall, "Design of High-Toughness Laminar Zirconia Composites," Am. Ceram. Soc. Bull., 71 [6] 969-73 (1992).

${ }^{6}$ R. K. Roeder, K. J. Bowman, and K. P. Trumble, "Texture and Microstructure Development in $\mathrm{Al}_{2} \mathrm{O}_{3}-$ Platelet Reinforced Ce- $\mathrm{ZrO}_{2} / \mathrm{Al}_{2} \mathrm{O}_{3}$ Laminates Produced by Centrifugal Consolidation," Textures Microstruct., 24, 43-52 (1995).

${ }^{7}$ E. Lucchini and O. Sbaizero, "Alumina/Zirconia Multilayer Composites Obtained by Centrifugal Consolidation," J. Eur. Ceram. Soc., 15, 973-81 (1995).

${ }^{8}$ P. Boch, T. Chartier, and M. Huttepian, "Tape Casting of $\mathrm{Al}_{2} \mathrm{O}_{3} / \mathrm{ZrO}_{2} \mathrm{Lam}-$ inated Composites," J. Am. Ceram. Soc., 69 [8] C-191-C-192 (1986).
${ }^{9}$ K. P. Plucknett, C. H. Caceres, C. Hughes, and D. S. Wilkinson, "Processing of Tape-Cast Laminates Prepared from Fine Alumina/Zirconia Powders," J. Am. Ceram. Soc., 77 [8] 2145-53 (1994).

${ }^{10}$ K. P. Plucknett, C. H. Caceres, F. Fremont, and D. S. Wilkinson, "TapeCast $\mathrm{Al}_{2} \mathrm{O}_{3} / \mathrm{ZrO}_{2}$ Composite Laminates," Ceram. Eng. Sci. Proc., 13 [9-10] 873-80 (1992).

${ }^{11}$ K. P. Plucknett, C. H. Caceres, and D. S. Wilkinson, "Tape-Casting of Fine Alumina/Zirconia Powders for Composite Fabrication," J. Am. Ceram. Soc., 77 [8] 2137-44 (1994).

${ }^{12}$ P. S. Nicholson, P. Sarkar, and X. Haung, "Electrophoretic Deposition and Its Use to Synthesize $\mathrm{ZrO}_{2} / \mathrm{Al}_{2} \mathrm{O}_{3}$ Micro-Laminate Ceramic/Ceramic Composite," J. Mater. Sci., 28, 6274-78 (1993).

${ }^{13}$ C. S. Smith, A Search for Structure: Selected Essays on Science, Art, and History. MIT Press, Cambridge, MA, 1981.

${ }^{14}$ B. V. Velamakanni, J. C. Chang, F. F. Lange, and D. S. Pearson, "New Method for Efficient Colloidal Particle via Modulation of Repulsive Lubricating Hydration Forces," Langmuir, 6, 1323-25 (1990).

${ }^{15}$ J. C. Chang, F. F. Lange, and D. S. Pearson, "Viscosity and Yield Stress of Alumina Slurries Containing Large Concentrations of Electrolyte," J. Am. Ceram. Soc., 77 [1] 19-26 (1994).

${ }^{16}$ J. A. Yanez, T. Shikata, F. F. Lange, and D. S. Pearson, "Shear Modulus and Yield Stress Measurements of Attractive Alumina Particle Networks in Aqueous Slurries," J. Am. Ceram. Soc., 79 [11] 2917-24 (1996).

${ }^{17} \mathrm{M}$. Menon and I-W. Chen, "Bimaterial Composites via Colloidal Rolling Techniques: II, Sintering Behavior and Thermal Stresses," J. Am. Ceram. Soc., 82 [12] 3422-29 (1999)

${ }^{18} \mathrm{M}$. Menon and I-W. Chen, "Bimaterial Composites via Colloidal Rolling Techniques: III, Mechanical Properties," J. Am. Ceram. Soc., 82 [12] 3430-40 (1999).

${ }^{19}$ N. Casson, "A Flow Equation for Pigment-Oil Suspensions for Printing Ink"; p. 84 in Rheology of Disperse Systems. Edited by C. C. Mills. Pergamon Press, New York, 1959.

${ }^{20}$ W. F. Hosford and R. M. Caddell, Metal Forming: Mechanics and Metallurgy. PTR Prentice Hall, Englewood Cliffs, NJ, 1983.

21'"NIH Image," developed by U.S. National Institutes of Health; available at National Technical Information Service, Springfield, VA.

${ }^{22} \mathrm{~A}$. Bleier and C. G. Westmoreland, "Effects of $\mathrm{pH}$ and Particle Size on the Processing of and the Development of Microstructure in Alumina-Zirconia Composites," J. Am. Ceram. Soc., 74 [12] 3100-11 (1991).

${ }^{23}$ S. L. Hwang and I-W. Chen, "Grain Size Control of Tetragonal Zirconia Polycrystals Using Space Charge Concepts," J. Am. Ceram. Soc., 73 [11] 3269 77 (1990)

${ }^{24}$ R. J. Horn, "Surface Forces and Their Action in Ceramic Materials," J. Am. Ceram. Soc., 73 [5] 1117-35 (1990).

${ }^{25}$ F. H. Norton, "Fundamental Study of Clay: VIII, A New Theory for the Plasticity of Clay-Water Masses," J. Am. Ceram. Soc., 31 [8] 236-41 (1948).

${ }^{26}$ B. Schwartz, "Fundamental Study of Clay: XII, A Note on the Effect of the Surface Tension of Water on the Plasticity of Clay," J. Am. Ceram. Soc., 35 [2] 41-43 (1952).

${ }^{27}$ W. D. Kingery and J. Francl, "Fundamental Study of Clay: XIII, Drying Behavior and Plastic Properties," J. Am. Ceram. Soc., 37 [12] 596-602 (1954).

${ }^{28}$ A. W. Adamson, Physical Chemistry of Surfaces, 4th Ed.; pp. 54-55. Wiley, New York, 1982.

${ }^{29}$ L. R. Fisher and J. N. Israelachivili, "Direct Measurement of the Effect of Meniscus Forces on Adhesion: A Study of the Applicability of Macroscopic Thermodynamics to Microscopic Liquid Interfaces," Colloid Surf., 3, 303-19 (1981)

${ }^{30}$ J. N. Israelachivili, "Adhesion Forces Between Surfaces in Liquids and Condensable Vapors," Surf. Sci. Rep., 14, 109-59 (1992).

${ }^{31}$ R. J. Hunter, Foundations of Colloid Science, Vols. 1 and 2. Oxford University Press, New York, 1992.

${ }^{32}$ M. A. Janney and G. Y. Onada, "Particulate Mechanics of Highly Loaded Ceramic Systems"; pp. 615-26 in Advances in Ceramics, Vol. 21, Ceramic Powder Science. Edited by G. L. Messing, K. L. Mazdiyasni, J. W. McCauley, and R. A. Haber. American Ceramic Society, Westerville, OH, 1987.

${ }^{33}$ G. Y. Onada and M. A. Janney, "Application of Soil Mechanics Concepts to Ceramic Particulate Processing"; pp. 53-74 in Advances in Powder Technology. Edited by G. Y. Chin. American Society for Metals, Metals Park, OH, 1982.

${ }^{34}$ S. L. Semiatin and H. R. Piehler, "Formability of Sandwich Sheet Materials in Plane Strain Compression and Rolling," Metall. Trans. A, 10A, 97-107 (1979).

${ }^{35}$ P. S. Steif, "On Deformation Instabilities in Clad Metals Subjected to Rolling," J. Appl. Metalworking, 4 [4] 317-26 (1987).

${ }^{36}$ W. Michaeli, Extrusion Dies for Plastics and Rubber, 2nd Ed.; pp. 234-38. Oxford University Press, New York, 1984.

${ }^{37} \mathrm{I}-\mathrm{W}$. Chen, J. Winn, and M. Menon, "Application of Deformation Instability to Microstructure Control in Multilayer Ceramic Composites," Mater. Sci. Eng., in press. 